\title{
DESENVOLVIMENTO SUSTENTÁVEL E CRISE AMBIENTAL: EXERCÍCIO DA CIDADANIA PARTICIPATIVA DIANTE DA QUESTÃO AGRÁRIA NA PERSPECTIVA DO DIREITO
}

Iranice Gonçalves Muniz

Pós-Doutoranda da Universidade Federal da Paraíba, Brasil no PPGCJ/UFPB. Doutora e mestre em Direito Público pela Universitat Pompeu Fabra, Barcelona, Espanha. Professora titular do Centro Universitário de João Pessoa, Paraíba, Brasil.

Fernando Joaquim Ferreira Maia Doutor e Mestre em Direito pela UFPE, Especialista em Direito Processual Civil pela UFPE, Professor Adjunto-II do Departamento de Ciências Sociais da UFRPE.

\section{Resumo}

O presente trabalho tratará da participação política dos camponeses na luta pela reforma agrária no Brasil como um exercício de cidadania para uma real democracia no meio rural. O objetivo principal é demonstrar que, mesmo indo contra o modelo de desenvolvimento econômico que centraliza a propriedade da terra em uma minoria da população, os camponeses, num ato de resistência, são capazes de se organizar e enfrentar os poderes dominantes (latifúndio e judiciário) em busca da democratização da terra. Partiu-se das seguintes indagaçóes: A desapropriação de propriedades improdutiva contribui para o desenvolvimento sustentável? Como se dão as ocupações de propriedade? Como se manifesta o Poder Judiciário diante dos conflitos agrários no Brasil? Metodologicamente, utilizou-se de levantamento bibliográfico nacional e internacional de temas como: sustentabilidade ambiental, função social da propriedade, constituiçáo e propriedade privada, direitos humanos, democracia e cidadania para atingir o objetivo do tema proposto.

\section{Palavras-chave}

Cidadania participativa; Sustentabilidade; Crise ambiental; Questão agrária.

\section{Abstract}

This paper will address the political participation of peasants in the struggle for land reform in Brazil as an exercise of citizenship for a real democracy in the countryside. The 
main objective is to demonstrate that, even going against the economic development model that centralizes the ownership of land on a minority of the population, the peasants, in an act of resistance, are able to organize and confront the dominant powers (landlordism and judiciary) in pursuit of democratization of land. Started from the following questions: The expropriation of unproductive properties contributes to sustainable development? How property occupation occur? How the Judiciary Power react to agrarian conflicts in Brazil? Methodologically, it was employed a national and international literature review of topics such as: environmental sustainability, social function of property, constitution and private property, human rights, democracy and citizenship to achieve the objective of the proposed theme.

\section{Key words}

Participatory Citizenship; Sustainability; Environmental crisis; Agrarian question.

\section{Introdução}

O presente trabalho tratará, da participação política dos camponeses na luta pela reforma agrária no Brasil como um exercício de cidadania para uma real democracia no meio rural. O objetivo principal é demonstrar que, mesmo indo contra o modelo de desenvolvimento econômico que centraliza a propriedade da terra em uma minoria da população, os camponeses, num ato de resistência, são capazes de se organizar e enfrentar os poderes dominantes (latifúndio e judiciário) em busca da democratização da terra, e o respeito aos direitos humanos de quem vive e sobrevive no meio rural. As propriedades reivindicadas pelos camponeses, no estado da Paraíba, Brasil, na sua grande maioria são propriedades que não cumpre a função social, ou seja, que deixam de observar os requisitos estabelecidos na Constituição de 1988 - utilização adequada dos recursos naturais disponíveis e a preservação do meio ambiente; observância das disposiçóes que regulam as relaçóes de trabalho; e exploração que favoreça o bem-estar dos proprietários e dos trabalhadores.

Dessa forma partimos das seguintes indagaçôes: A desapropriação de propriedades improdutiva ou que não cumpre a função social contribui para o desenvolvimento sustentável? Como se dão as ocupaçóes de propriedade? Como se manifesta o papel do Poder Judiciário diante dos conflitos agrários no Brasil?

Os assentamentos rurais da reforma agrária são formas de conquista do território, elemento importante para permanecer na terra. A sua conquista possibilita a formaçáo de novas territorialidades, processo de ocupação e resistência que reconstrói o espaço social. Tais assentamentos configuram-se como elementos recentes da paisagem agrária brasileira, 
frutos de lutas incansáveis dos camponeses organizados e marginalizados ao longo da história fundiária.

Os assentamentos se formam através da desapropriação da propriedade pelo Poder Executivo. Desapropriada e parcelada a terra, inicia-se uma outra batalha etapa, a de tornar os assentamentos como unidades produtivas capazes de proporcionar uma renda mínima para o sustento das famílias camponesas beneficiadas.

No estado da Paraíba, por exemplo, existem vários assentamentos rurais localizados na Zona da Mata Paraibana, criados pelo Instituto Nacional de Colonização e Reforma agrária (INCRA) através da desapropriação de vária fazenda, desde a promulgação da Constituição Federa de 1988.

Para o desenvolvimento da presente pesquisa, se fizeram necessárias participaçóes nas reuniôes da Comissão Pastoral da Terra; do Memorial das Ligas Camponesas; do Grupo de pesquisa Gestar: território, trabalho e cidadania; leituras de textos espanhóis que abordam a funcão social da propriedade; e de textos de autores que abordam de formas diferentes o conceito de Desenvolvimento Sustentável, em especial seus pressupostos e suas diferentes interpretaçóes. Foram também realizadas leituras em processos judiciais que envolveram camponeses na luta pela terra e que hoje são assentados da reforma agrária; leitura sobre a economia dos assentamentos rurais; práticas alternativas de produçáo e comercialização de alimentos sem agrotóxicos.

Essas leituras, obviamente, serviram de fundamentação teórica para a elaboração do presente trabalho. Foram feitos levantamentos bibliográfico nacional e internacional de temas como: sustentabilidade ambiental, função social da propriedade, constituiçáo e propriedade privada, direitos humanos, democracia e cidadania para atingir o objetivo do tema proposto.

\section{Crise Ambiental e Desenvolvimento Sustentável}

A compreensão da crise ambiental de nossa época proclama o entendimento do processo histórico de reintegração de saberes diversos, a partir de uma tentativa de sistematizaçáo total do ambiente, engendrando - nas trilhas do processo histórico da Revolução Industrial - uma compartimentalização fracionada dos saberes científicos. Tal fracionamento dos saberes científicos, associado ao menosprezo dos saberes culturais podem provocar um estorvo para a problematização e internalização da complexidade ambiental, reduzindo-a a um simulacro sistêmico e homogeneizante da questão ambiental. (LEFF, 2010, p. 40)

A perspectiva jurídica e as dimensóes da chamada crise para o Direito, desencadeia um processo para além das fronteiras, diante dos problemas de escassez e utilização dos 
recursos naturais, que póem em cheque as necessidades humanas, os princípios em que se fundamentam a proteção dos direitos fundamentais, a dignidade da pessoa humana, a sadia qualidade de vida, em paradoxo com o desenvolvimento humano, social e econômico e, obviamente, sustentável.

As conjecturas envoltas à problemática ambiental e o poder internacionalmente articulados, veem-se ideologicamente instituídos no próprio saber. A progressiva degradação ambiental associa-se de modo simbiótico, simbólico e ideológico a uma reconstrução do consumo sustentável, que contribui também para a temerária compleição de um consumismo revestido com uma maquiagem de desenvolvimento sustentável. Essa problemática não se refere somente ao meio natural, mas também ao meio social e aos poderes políticos locais.

O desenvolvimento sustentável nos moldes como é abordado no senso comum, conjura para uma "neutralização" ideológica alheia as contradiçóes ambientais de nossa época, bem como alquebra a complexidade ambiental, na medida que instiga a redução do ambiente a um estratagema ecológico abstrato e alienado.

É importante destacar, por exemplo, que durante os processos de contato e interação dos conhecimentos do meio natural e do meio social, quando são postos em marcha projetos e programas voltados ao espaço rural, se estabelece uma dinâmica que faz emergir uma série de heterogeneidades, especialmente considerando que se ampliam conexóes entre os diversos atores sociais.

Nesse cenário, o ambiente e a sustentabilidade sofrem de um impacto socioambiental - historicamente e ideologicamente construído - perfazendo a legitimação do trato do ambiente como um mero objeto do desenvolvimento econômico. Em outras palavras, como um limite da sociedade civil mundial, quando na verdade tal abordagem retórica dissimula os comprometimentos ideológicos de encarar o ambiente com uma visão estritamente ecológico. Estas estratégias epistemo-ideológicas, segundo Leff (2010, p. 63) "não apenas desconhecem o processo histórico de distinção, constituição e especificidade das ciências e dos saberes, mas também as estratégias de poder no conhecimento que cobrem o terreno ambiental”. Para o autor (2010), a crise ambiental é antes de tudo uma crise civilizatória, amalgamada a uma crise do próprio conhecimento ${ }^{1}$, ensejando a imprescindível necessidade de compreender o ser na contemporaneidade, compreendendo a complexidade com vistas a abrir perspectivas para reconstruir e reapropriar-se do mundo.

1 A crise de paradigmas aduzida por Leff (2010), propala-se com maior rigor nos meandros do ensino jurídico e do seu conhecimento. Este é ainda fortemente marcado pelo paradigma epistemológico da filosofia da consciência, fundado na premissa de um sujeito isolado cognoscente, sendo as manifestaçóes de vida e relaçóes humanas demasiadamente fetichizadas e funcionalizadas. 
O debate do desenvolvimento sustentável tem permitido um discurso relacionado com direitos humanos despolitizados ou esvaídos de sentido, sendo menosprezada a problemática do debate entre incluídos e excluídos. Caso não sejam considerados projetos coletivos de transformação sócio-política associados a lógica de não-intervenção no ambiente ou na liberdade política, pode-se tornar temerário, pernicioso e irresponsável encarar o direito o "desenvolvimento sustentável" ou a "democracia" como nova dimensão dos direitos humanos.

A inclusão dos indivíduos no consumo "sustentável" ou no arcabouço democrático-liberal preexistente vem a ser insuficiente, a partir do momento que são relegados ao status de seres humanos "em geral", detentores desses ditos e escritos "direitos humanos universais". Podemos fazer um paralelo aqui com o insight de Hannah Arendt quanto aos refugiados:

A concepção dos direitos humanos baseada na suposta existência de um ser humano como tal rompeu-se no exato momento em que aqueles que declaravam acreditar nesta concepção foram, pela primeira vez, confrontados com pessoas que tinham perdido, de fato, todas as demais qualidades e relações específicas, exceto a de seguir sendo humanas.(ARENDT, 1989)

O cotejo aduzido acima reproduz que a degradação ecológica globalizada não pode considerar estratégias de enfrentamento neutras igualmente globais, ignorando as interpenetraçôes das relaçôes de poder nos debates de gênero, cidadania, religião, identidade étnica, etc. Nesta senda, as açôes filantrópicas de cunho sustentável precisam ser esmiuçadas no seu âmago, pois, apesar de servirem - pontualmente - como mecanismos paliativos para a conquista e tutela de medidas menos degradante ao ambiente, contribuem a um só tempo, como estratégia contraditória que legitima ideologicamente, materialmente e simbolicamente o processo de acumulação de capital que nega a própria sustentabilidade.

O espaço rural é o território que geralmente reflete as disputas e tensóes entre os diferentes projetos de ocupação, preservação e uso da terra. O espaço rural é o espaço dos indígenas, dos extrativistas, dos quilombolas, dos pescadores, dos ribeirinhos, das comunidades tradicionais, dos camponeses em geral, que cada vez mais tentam se organizar, e atuar na defesa de seus interesses.

Assim, a luta pela reforma agrária também se realiza nesse espaço (territórios), geralmente em disputa com visóes ambientalistas diversas que muitas vezes ignoram a dimensão social e os princípios da justiça social e ambiental. É no espaço rural brasileiro que se encontram os principais ecossistemas, como a floresta amazônica, o cerrado, o pantanal, os manguezais, as bacias hidrográficas, as lagoas, o olho d'água, as cacimbas e as nascentes de seus rios. 
A luta pela conservação, preservação e manutenção desses espaços tem mobilizado os movimentos sociais na defesa do meio ambiente, na tentativa de articular os interesses ecológicos com justiça social e estabelecer uma visão crítica sobre os grandes projetos econômicos de desenvolvimento que utilizam-se da exploração dos recursos naturais da terra.

\section{Democratização da Propriedade Rural e sua Crise}

O Brasil tem o imenso território com mais de oito milhóes e meio de quilômetros quadrados no qual poucos possuem muitos hectares de terra e muitos não possuem nada ou quase nada. $\mathrm{O}$ empobrecimento de grande parte da população que se encontra nesses dois extremos é visível em quase todas as regióes da Federação brasileira. É claro que a disputa pela propriedade da terra não é exclusiva da nossa sociedade. Entretanto, o conflito agrário brasileiro é um dos mais expressivos do mundo por ser um conflito nítido, com organizaçôes da sociedade civil, através dos movimentos sociais organizados.

Para Santa Rosa (1963) A concentração da propriedade por falta da aplicação adequada das leis intensificou a histórica resistência dos camponeses contra o poder do latifúndio no Brasil, em especial no nordeste do país, onde milhares de pessoas tiveram que deixar as propriedades rurais. Muitos foram forçados a mudar para as grandes cidades em busca de melhores condiçóes de vida.

Desde a promulgação da Constituição de 1988, no Brasil, as ocupações de terras improdutivas têm sido uma prática constante em todo o país. A primeira fase das ocupaçóes inicia-se com um trabalho de conscientização, realizado por representantes das associaçôes rurais e do movimento dos trabalhadores rurais sem terra (MST).

O lugar e a forma da ocupação ficam abertos para debate. Segundo Muniz (2000) as decisóes amadurecem pelo período de alguns meses por parte de um pequeno grupo de camponeses (trabalhadores rurais sem terra) dispostos a ocupar a propriedade rural. A entrada na propriedade constitui-se num ato consumado.

Estas ocupações recebem o apoio de instituições não governamentais com grande repercussão no meio rural. Há registro de depoimentos de pessoas que participaram de ocupaçóes que atestam essa movimentação: fiquei sabendo do conflito pelo rádio e pela televisão. Como fui trabalhador nas fábricas dessa região há mais de 20 anos, me uni aos que se organizaram e entraram na terra ${ }^{2}$.

De início, o conflito é estabelecido entre os proprietários que têm o título de propriedade e os camponeses sem terra. Os movimentos sociais reivindicam/ exigem a aplicação

2 Relato de uma testemunha num processo de Reintegração de Posse na Comarca de Cruz do Espírito Santo, estado de Paraíba, Brasil, em abril de 1997. 
dos preceitos constitucionais como: o cumprimento da função social da propriedade, o respeito à dignidade da pessoa humana, a erradicação da pobreza e da marginalização. E, encontram fundamentação tanto nas normas constitucionais como na doutrina mais atualizada. Para Rawls, as circunstancias da justiça refletem as condições históricas sob as quais as sociedades democráticas contemporâneas existem. (RAWLS, 2003)

De acordo com Perlingieri (1997), o conteúdo da função social assume um papel de tipo promocional, no sentido de que a disciplina das formas de propriedade e as suas interpretaçóes deveriam ser praticadas para garantir e promover os valores sobre os quais a legislação se baseia.

A luta dos camponeses por uma reforma agrária no Brasil representa o pleno exercício da cidadania. Parece impossível, no quadro social, político, econômico e jurídico desses problemas, deixar de considerar os instrumentos de participaçáo que os camponeses, titulares dos direitos humanos fundamentais, usam para defender a sua dignidade. A ocupação de terras, sejam urbanas ou rurais, é um instrumento utilizado para chamar a atenção do poder público para a observância dos princípios constitucionais da dignidade da pessoa humana, da cidadania, da erradicação da pobreza e da marginalização e da prevalência dos direitos humanos dentre outros, previstos na Constituição brasileira de 1988.

A ocupação de propriedades improdutivas, ou seja, que não cumprem a função social, pelos camponeses organizados é um momento de importância fundamental para o debate, não apenas no que se refere à função social da propriedade no Título II dos direitos e garantias fundamentais, mas, sobretudo, o debate sobre a dignidade humana de milhares de famílias camponesas.

Os conflitos entre os camponeses e os donos de propriedades que não cumpre a função social quase sempre viram demandas no poder judiciário. Com a ordem de despejo emitida pelo juiz competente cria-se uma intolerância por parte do proprietário, dos camponeses despejados e do poder judiciário que quer ver sua decisão cumprida. Consequentemente, solicita-se a força policial. O despejo é realizado depois de alguns dias. Em muitos casos, esses despejos são feitos por meio de açóes violentas ${ }^{3}$ numa briga entre os membros da polícia militar e os camponeses, culminando com a prisão de alguns líderes. Posteriormente, inicia-se um processo criminal contra os camponeses, sob a alegação de desobediência à ordem judicial, formação de quadrilha ou bando, entre outros delitos.

Após o despejo, várias pessoas se unem aos acampados ou aos antigos habitantes da propriedade rural, e todos são incentivados a permanecer na luta pela expropriação daquela propriedade. Muitos dos conflitos deram origem a livros, documentários e filmes,

3 Veja, por exemplo, os conflitos de "El Dorado de Carajás", "Corumbiara" e "Texerinha" publicados nos cadernos do MST de 1995 e 1996. 
e ajudam a informar os moradores no meio rural e os apoiadores da reforma agrária. O apoio das ONGs contribui para a conscientização desses camponeses sem terra no sentido de fazer parte do processo de consolidaçáo da democracia e da cidadania no meio rural. Dessa forma, a propriedade ocupada passa a ser um alvo político de interesses opostos.

Esta experiência, que até o momento da ocupaçáo se limitava a desafiar o proprietário de terra, torna-se mais complexa, visto que envolve participar numa luta aberta contra os poderes públicos, principalmente os membros do Executivo e do Poder Judiciário, lutando pelo direito à propriedade que, do ponto de vista dos camponeses, não cumpre com a sua função social, enquanto que, do ponto de vista do Poder Judiciário, trata-se de uma propriedade privada que foi invadida.

Depois de vários meses ou anos vivendo num acampamento, os camponeses veem a propriedade ser desapropriada por decreto do Governo Federal (Poder Executivo). Para ilustrar, cita-se, por exemplo, quase todas as terras que foram alvo de ocupaçōes feitas no estado da Paraíba foram desapropriadas pelo governo federal ou pelo governo estadual.

No que se refere aos ensinamentos de Bobbio (1992), é possível afirmar que a satisfação das necessidades vitais do ser humano é uma condição para a existência da democracia. Ou seja, enquanto houver uma propriedade rural que náo cumpre com a sua função social e camponeses sem terra, o processo democrático brasileiro será sempre frágil e ambíguo. Este é, justamente, o argumento de velar pela dignidade humana, o que justificaria as ocupações de propriedades que não cumprem com a sua função social como forma de pressão para a consolidação da democracia no meio rural brasileiro. Para Gomez Montoro (2001), este valor negativo da propriedade, como defesa da esfera social diante do poder público justifica outro elemento substancial do constitucionalismo, a saber, a participação do indivíduo no Estado.

Pode-se dizer que o Brasil chega ao século XXI sem ter resolvido o problema que envolve a democracia no meio rural. Sem dúvida, a demora de uma reforma agrária por parte dos Poderes Legislativo e Executivo terá repercussōes no Judiciário, que destina-se a solucionar as demandas individuais ou coletivas, inclusive aquelas que vêm das omissóes do Poder Público.

\section{O Poder Judiciário e a Democracia no Meio Rural Brasileiro}

A intervenção do Poder Judiciário é fundamental no caso das demandas que envolvem o interesse social e, em especial, a função social da propriedade, pois revela que os cidadãos são obrigados a recorrer aos meios judiciários. Essa intervenção resulta numa dimensão jurídica do político, pois as ocupaçôes de propriedades rurais, que seriam atos políticos, se transformam em controvérsias ou demandas pelo respeito à funçáo social da 
propriedade constitucionalizada na Constituição de 1988. Embora, Bobbio (1997), em sua obra o futuro da democracia, adverte que, se a democracia náo consegue derrotar por completo o poder das oligarquias, é ainda menos capaz de ocupar todos os espaços nos quais se exerce um poder que toma decisóes vinculatórias para um inteiro grupo social.

As frequentes ocupaçóes de terra promovidas em massa em todo o país em prol dos direitos humanos fundamentais das pessoas envolvidas ainda são interpretadas pelas autoridades judiciais brasileiras como apropriaçóes ilícitas, passíveis de sançôes tanto civil como penal. Com isso, nos perguntamos: qual é o papel do Poder Judiciário diante dos conflitos agrários no Brasil?

Embora a razão política seja determinante na tarefa interpretativa de qualquer regra do Direito, os princípios políticos que a inspiram têm uma relevância acentuada na norma constitucional. Visto que a inteira Constituição, enquanto norma, tenta responder e explicar judicialmente todo um conjunto complexo de elementos políticos, sociais e ideológicos que não é possível que o intérprete o desconsidere. Para López y López (1988), esta exigência é prius indeclinável para que se achegue à Constituição com coragem de interpretá-la do ponto de vista jurídico, ou seja, pelo menos pressupondo um mínimo de certeza no texto; e isso além da sua ideologia particular, que poderia se refletir na sua tarefa, e na proposta de soluçóes particulares.

A supremacia constitucional envolve uma reordenação geral do ordenamento por meio de um postulado essencial da interpretação das normas à luz da Constituição para todos os Juízes e Tribunais.

No Brasil, a Constituição de 1988 dedicou um capítulo III do Título IV ao Poder Judiciário. A denominação de poder enfatiza o caráter de independência que se atribui ao poder jurisdicional ao serviço de uma função de proteção do Direito, que informa todo o texto constitucional. Esta caracterização do poder judiciário como um poder independente é um reflexo da doutrina da divisão de poderes e está relacionada com a definição dada pela Constituição no artigo $2^{\circ}$, do Título I, por meio do qual o Brasil se constitui como um Estado Democrático de Direito.

Os três poderes estão intimamente relacionados, e o Poder Judiciário deve sintonizar sua atuação em consonância com a legislação vigente, utilizando a bússola da dignidade da pessoa humana, que orienta todo o ordenamento jurídico. E assim, náo é possível desconsiderar o que a Constituição estabelece sobre a questão agrária.

No que se refere a questão agrária brasileira, a Assembleia Nacional Constituinte de 1987/1988 a constitucionalizou, dedicando-lhe um capítulo no Título VII da Constituição de 1988, com regulamentação na lei agrária no ${ }^{\circ}$ 8.629/1993. Tal lei desenvolve os preceitos constitucionais sobre a reforma agrária. 
Em 2003, o Poder Executivo lançou um plano nacional de reforma agrária, conhecido como II Plano Nacional de Reforma Agrária. Este plano teve início nos movimentos sociais, com a participação de milhares de famílias camponesa em quase todos os estados da federação.

Quando se questiona o direito de propriedade como um direito fundamental, observa-se que questão agrária no Brasil é extremamente contraditória e que dá ao Poder Judiciário o inevitável papel principal de administrar a justiça e aplicar os preceitos constitucionais, visto que somente o Poder Judiciário tem o poder de decidir casos de conflitos e interesses contrários no seio do espaço rural.

Entretanto, o Poder Judiciário não pode fechar os olhos aos casos de concentração de propriedade rural que permite o uso abusivo de terra por parte dos proprietários que mantêm propriedades improdutivas ou que possuem propriedades economicamente "produtivas", mas que não cumprem com a função social. Os juízes devem aplicar os valores e princípios alistados na Constituição brasileira de 1988, que se situa como marco jurídico da democracia. Ou seja, os juízes não devem perder de vista o princípio da dignidade humana dos afetados por tal concentração. Enterría , ao falar sobre a realidade espanhola, diz que "a interpretação da Constituição deve perder o legalismo". O Juiz: deve adquirir uma nova responsabilidade, que em boa medida venha a torná-lo um personagem muito mais relevante na nossa vida jurídica do que até agora se permitiu. Deixará de ser o reine subsumtions apparat, o mecanismo puro de subsunção de fatos nas normas, neutro e desinteressado no problema de fundo que lhe é apresentado, para passar a ser um analista desse problema decomposto em seus diferentes elementos de valor e julgá-los a partir dos valores que a própria Constituição destaca como superiores. (GARCÍA ENTERRÍA, 1980).

Ruiz Perez (1981, p.165) adverte que os sistemas jurídicos não constituem um todo isolado e suficiente, até mesmo os de tipo predominantemente codificados. A zona de incerteza, de dúvida e até de imprevisibilidade, é consideravelmente maior em comparação com os considerados até então. Por combiná-los com a interpretação judicial, obtemos mais margem para criatividade e valorizaçáo do que, à primeira vista, parece ser o princípio da sujeição total do juiz à lei, não resultando no grau de absoluto definido por Savigny, que diz que o juiz é um simples aplicador mecânico de uma norma previamente dada, conceito que parece ter sido superado. Além disso, não devemos nos esquecer de que um Estado Democrático de Direito e a democracia em geral baseiam-se na admissão da presença, e até mesmo na necessidade, de interesses opostos.

Nesse contexto, e se uma determinada propriedade rural não cumpre a sua função social, perde a garantia que a justifica. $\mathrm{Na}$ verdade, se a função social é uma noção que surge precisamente em busca de uma legitimidade da propriedade privada, não seria um exagero pensar que, em sua ausência, sendo retirada a tutela jurídica do domínio, em 
situaçóes concretas de conflitos, para garantir o interesse da coletividade. Para Colina Garea (1997), o direito de propriedade é um direito fundamental debilitado.

Para os camponeses e os demais habitantes do espaço rural a terra é mais que uma fonte de trabalho e alimento; representa a cultura, história, tradição, ancestrais, sonhos, vida e proteção. A luta em defesa da terra e do meio ambiente é a luta pela vida, pela dignidade humana, pela cidadania ambiental e pela democracia no campo.

É no espaço rural, onde o sentimento pela terra é mais significativo, pois, ela é a principal fonte de vida para uma parcela significativa da população, e cuja estrutura de representação simbólica garante a continuidade das tradiçóes, costumes e valores para as geraçóes futuras. Para Rey Martínez (1994) a ideia de propriedade socializada surge no plano normativo como consequência da crise do liberalismo ligada à exigência da sua democratização e ao descobrimento das possibilidades de intervenção pública na economia...A concentração da terra, dos meios de produção e da renda nas mãos de grupos econômicos, imposta pelo sistema capitalista, que transforma a natureza em objeto de produção, sem limite, ampliou as possibilidades e as formas de promover a desigualdade social, econômica, cultural e regional, ou seja, os benefícios gerados pelo atual modelo de desenvolvimento capitalista hegemônico se restringem a uma pequena minoria, no entanto, seus efeitos são distribuídos à uma grande maioria dos habitantes da terra.

Hoje, a crise ambiental decorrente das intransigências desse modelo de desenvolvimento adotado pela sociedade atinge a todos, principalmente os que habitam no espaço rural. O espaço rural é o território que geralmente reflete as disputas e tensóes entre os diferentes projetos de ocupação, preservação e uso da terra. O espaço rural é o espaço dos indígenas, dos extrativistas, dos quilombolas, dos pescadores, dos ribeirinhos, das comunidades tradicionais, dos camponeses em geral. Para os camponeses e os demais habitantes do espaço rural a terra é mais que uma fonte de trabalho e alimento; representa a cultura, história, tradição, ancestrais, sonhos, vida e proteção. A luta em defesa da terra e do meio ambiente é a luta pela vida, pela dignidade humana, pela cidadania ambiental e pela democracia no campo. A terra sempre foi e continua sendo um meio de produção essencial, na medida em que é sobre ela que quase todo o processo produtivo se desenvolve e que os seres humanos se estabelecem (REYDON, 2007).

A problemática ambiental enunciou a emergência de novos direitos, portanto, necessita de uma ampliação significativa do conceito de cidadania que transcenda a relação entre o individuo e o Estado (SILVA-SÁNCHEZ, 2010).

\section{Conclusões}

A experiência dos conflitos agrários demonstrou que os camponeses que ocupam as propriedades discordam com a atitude de alguns juízes que, ao aplicar a lei em casos 
concretos, no que se refere aos conflitos, os analisam sob o ponto de vista limitado do delito penal. É evidente que, nos conflitos agrários, as ocupaçóes de terras não podem ser tratadas como casos policiais, visto que, ao contrário dos delinquentes comuns, que violam a lei, os agricultores sem terra que participam na luta pela reforma agrária agem por convicção política ou social. Assim, quando o ordenamento penal é utilizado na repreensão das manifestaçóes populares, este tem o papel de arma para a defesa de uma ordem estatal que se transforma em medida não adequada à democracia.

Com tudo isso, a questáo agrária propriamente dita até o momento não foi interpretada pelo Poder Judiciário como matéria constitucional, o que constitui uma postura não adequada diante da realidade da área rural brasileira. No exercício da cidadania, as famílias agrícolas enfrentam o modelo de sociedade baseado no direito de propriedade inviolável embora não seja absoluto..Falamos da posição do Poder Judiciário em relação com a interpretaçáo constitucional no que se refere aos conflitos no meio rural. No entanto, a questão agrária é complexa, e a Constituição se refere também à preservação do meio ambiente entre os requisitos do cumprimento da função social da propriedade no artigo 186: A função social é cumprida quando a propriedade rural atende, simultaneamente, segundo critérios e graus de exigência estabelecidos em lei, aos seguintes requisitos: I - aproveitamento racional e adequado; II - utilização adequada dos recursos naturais disponíveis e preservação do meio ambiente.

As perspectivas do direito e da justiça ambiental, sáo desafiadas pela crise ambiental da modernidade, incluindo-se aí os problemas de escassez de recursos essenciais à vida, bem como a segurança alimentar que põe à frente a questão do campo, as atividades agrárias, a vida no campo, os direitos do camponês e a dignidade da pessoa humana.

O desenvolvimento é uma realidade que confronta a complexidade ambiental, ao menosprezar o necessário trinômio humano, econômico e social, sem o qual não pode ser chamado de desenvolvimento e, uma vez preenchido há de ser sustentável em toda a dimensão jurídica e científica que o alberga, transcendendo fronteiras e limites do saber.

\section{Referências}

ARENDT, Hanah. As origens do totalitarismo. São Paulo: Cia das Letras, 1989.

BOBBIO, Norberto. A era dos Direitos, Rio de Janeiro, ed. Campos, 1992 (Trad. de Nelson Coutinho).

. O futuro da Democracia: uma defesa das regras do jogo. Rio de Janeiro: Paz e Terra, 1997.

COLINA GAREA, Rafael, La Función Social de La Propiedad privada, Barcelona: José María Bosch editor, 1997. 
GARCÍA ENTERRÍA, Eduardo, En prólogo a la obra de Bernard Schwartz, Los diez mejores jueces de la historia americana, Madrid: Civitas, 1980.

GOMEZ MONTORO, A., La titularidad de derechos fundamentales por personas jurídicas: un intento de fundamentación. Madrid: Revista Española de Derecho Constitucional, no. 62, 2001, p. 50.

LEFF, Enrique, Saber Ambiental: Sustentabilidade, racionalidade, complexidade, poder. Petrópolis, RJ: Vozes, 2010.

LÓPEZ Y LÓPEZ, Ángel M., La Disciplina Constitucional de la Propiedad Privada, Madrid, Tecnos, 1988.

MUNIZ, I. G., Protagonistas de um sonho: desafio da assessoria jurídica no campo, João Pessoa: Emprell, 2000, p. 53.

PERLINGIERI, Petro, Perfis do Direito Civil - Introduçáo ao Direito constitucional, Rio de Janeiro, Renovar, 1997.

RAWLS, John, Justiça como Equidade: uma reformulação. São Paulo: Martins Fonte, 2003.

REYDON, Batistan Philip. A regulação institucional da propriedade da terra no Brasil: uma necessidade urgente. Em: Dimensóes do Agronegócio Brasileiro: Políticas, Instituiçóes e Perspectivas. NEAD estudos no 15, Brasília: MDA, 2007.

REY MARTÍNEZ, Fernando, Fernando, La propiedad Privada en la Constitución Espańola, Madrid: Boletín oficial, Centro de Estudios Constitucionales, 1994.

RUIZ PEREZ, Salvador Joaquín, Juez y sociedad, Málaga: Universidad de Málaga, 1981.

SANTA ROSA, Virginio, O que foi o tenentismo? - Rio de Janeiro, Civilização Brasileira, 1963.

SILVA-SÁNCHEZ, Solange S. Cidadania Ambiental: novos direitos no Brasil. São Paulo: Annablume, 2010. 